\title{
Amyotrophic Lateral Sclerosis Descriptive Epidemiology: The Origin of Geographic Difference
}

\author{
Giancarlo Logroscino ${ }^{a, b}$ Marco Piccininni ${ }^{a}$ b \\ aDepartment of Basic Medical Sciences, Neuroscience and Sense Organs, University of Bari "Aldo Moro", Bari, \\ Italy; ${ }^{\mathrm{b}}$ Department of Clinical Research in Neurology, Center for Neurodegenerative Diseases and the Aging Brain, \\ University of Bari "Aldo Moro", "Pia Fondazione Cardinale G. Panico", Tricase, Italy
}

\section{Keywords}

Amyotrophic lateral sclerosis - Population-based study . Cohort - Registries · Global Burden of Disease · C9ORF72 . Incidence · Ancestry · Ethnicity · Geographic gradient

\begin{abstract}
Amyotrophic lateral sclerosis (ALS) epidemiology has rapidly developed in the last 30 years alongside the evolving changes in concepts in the field of clinical ALS and also due to the recent proposals of new classification system for motor neuron diseases. Many of these changes in the clinical scenario have been determined through the results of ALS population-based studies conducted in the last 20 years primarily in Europe. All the evidences converge to show that ALS risk is different across continents and ethnicities. In a European registry consortium named EURALS, ALS incident cases were drawn from a source population comprising almost 24 million people across Europe (ALS cases: 1028) and the estimated incidence was 2.2 per 100,000 person-years (py) for the general population. In contrast, other population-based studies have measured the lowest incidence in East Asia to be 0.89 per 100,000 py and in South Asia to be 0.79 per 100,000 py. A large part of Africa, Latin America and Asia does not have any population-based
\end{abstract}

(c) 2019 S. Karger AG, Basel studies. The origin of geographic difference in ALS incidence is a matter of debate. Probably, this is partly due to genes (C9ORF72) and partly due to environmental risk factors. The rapid disappearance of ALS Foci in Guam, Kii, and West Guinea underline the importance of changes in lifestyle and environmental factors. The Global Burden of Disease, a project aiming to describe the burden of all diseases and injuries across all the countries of the world with a standardized protocol, has collected heterogeneous sources of data to estimate the burden of motor neuron diseases. The demographic changes related to increased expectation of life and the growth of the world population indicate that the load of motor neuron disease is rapidly moving toward 400 thousand prevalent cases. The burden is expected to shift toward Asia and Africa in the next decades for the rapid increase of expectation of life of countries with high demographic impact.

(c) 2019 S. Karger AG, Basel

Amyotrophic lateral sclerosis (ALS) epidemiology has rapidly developed in the last 30 years alongside evolving changes of concepts in clinical ALS and also due to the recent proposals of new classification system for motor neuron diseases.

\section{KARGER}

E-Mail karger@karger.com www.karger.com/ned
Giancarlo Logroscino, $\mathrm{MD}, \mathrm{PhD}$

Department of Clinical Research in Neurology, Center for Neurodegenerative Diseases and the Aging Brain, University of Bari "Aldo Moro"/Pia Fondazione di Culto e Religione "Card. G. Panico", IT-73039 Tricase/Lecce (Italy)

E-Mail giancarlo.logroscino@uniba.it 
ALS is an inevitably fatal neurodegenerative disease with dominant clinical features determined by the neurodegeneration of the motor neurons system. In the last decade however, an array of studies has clearly shown that ALS is a multisystem disease involving other functional domains as cognition, behavior, the autonomic system, and the extrapyramidal motor system. The new diagnostic challenge is therefore the recognition of different phenotypes beyond classical ALS with involvement of only first and second motor neurons.

This has led to the development of a hypothesis of a new classification system that could be an advanced version of El Escorial Criteria (EEC) [1]. EEC have a substantial limitation in missing important clinical features as the rate of progression or functional effect or extended and multidomain distribution of symptoms and signs. The older cases are more likely to present additional clinical features. Many of these changes in the clinical scenario have been determined by the results of ALS populationbased studies conducted in the last 20 years primarily in Europe. All evidences converge to show that ALS risk is different across different continents and ethnicities. In this review, the focus is on the sources of geographic heterogeneity.

\section{Registry: The Instrument for ALS Data Collection}

In the ALS epidemiology, the construction in Europe of several population-based registries has been the critical methodological change in the collection of data.

The first was established in Scotland [2], starting in January 1989 with the main goal of studying the clinical features of motor neuron disease (MND) in populations (not in the clinic). In this registry, all patients were identified prospectively and were incident cases.

The key point is that the registry identified a reference population in a well-defined geographic area where all the possible sources of case identification were identified and they all became part of a diagnostic and follow-up process. Scotland had many of the characteristics needed for the success of being a registry: (a) relatively isolated country with a good national health system; (b) all people registered with a general practitioner with very few subjects looking for care outside the country; (c) accurate determination of numerators and denominators for incidence rate and survivorship with consequent comparison with the reference general population, relatively stable. Interestingly in all of Scotland for a population of about 5 million subjects, when the Scotland registry was launched, there were only 19 neurologists and 4 neurophysiologists who could perform electromyography, which is the key diagnostic exam to identify the neuronal damage of second motor neurons.

Similar ALS registries were built in the following years in Lancashire, England [3], Ireland [4], and 3 regions in Italy (Piemonte and Val D'Aosta; PARALS) [5]; Lombardia (SLALOM) [6] and Puglia (SLAP) [7]. The population-based registries in Europe measured a remarkably homogeneous incidence ranging from 1.7 to 2.3 cases per 100,000 person-years (py), much higher than about 1 per 100,000 py, reported in the most of previous studies. This was primarily due to the substantial improvement in the methods of data collection. An extensive search for ALS cases was provided in the catchment areas with many different approaches. There was the involvement of the patient associations. The active involvement of patients and their organizations in research was important and anticipated, many decades before, future initiatives primarily driven by patients in recent years as "patient like me" [8]. Other systematic improvement was the accurate followup in most registries with at least one visit every 6 months. The follow-up that was systematic in each registry determined the improvement of diagnostic accuracy with the exclusion of cases that were not ALS (named mimic syndromes) in the first years after first visit. ALS seems an easy diagnosis but needs confirmation. The mimic syndromes were close to $10 \%$ of cases in a registry after 3 years of follow-up [9]; multifocal motor neuropathy was the most common condition mistaken for ALS, accounting $22 \%$ of mimic syndromes in Ireland, while cervical spondylotic myelopathy was the most frequent in Scotland (19\%). The continuous follow-up determined the quality of diagnosis through new investigations and, particularly important, an extended period of observation. The assessment of lack of progression was the decisive clinical element to change the ALS diagnosis.

The interval onset diagnosis was another element measured systematically in the registries, a composite measure of aggressiveness of the course of disease and of the characteristics of the referral of the health system of the region. In Europe, the interval onset-diagnosis was about 1 year across all the registers. As in all neurodegenerative diseases, the goal is to have a shorter interval to start therapy as soon as possible [10].

Complete case ascertainment, improvement of the accuracy of diagnosis, homogenous estimation of numerators and denominators, and multiple sources for referral are the major qualities of all these systems.
Logroscino/Piccininni 


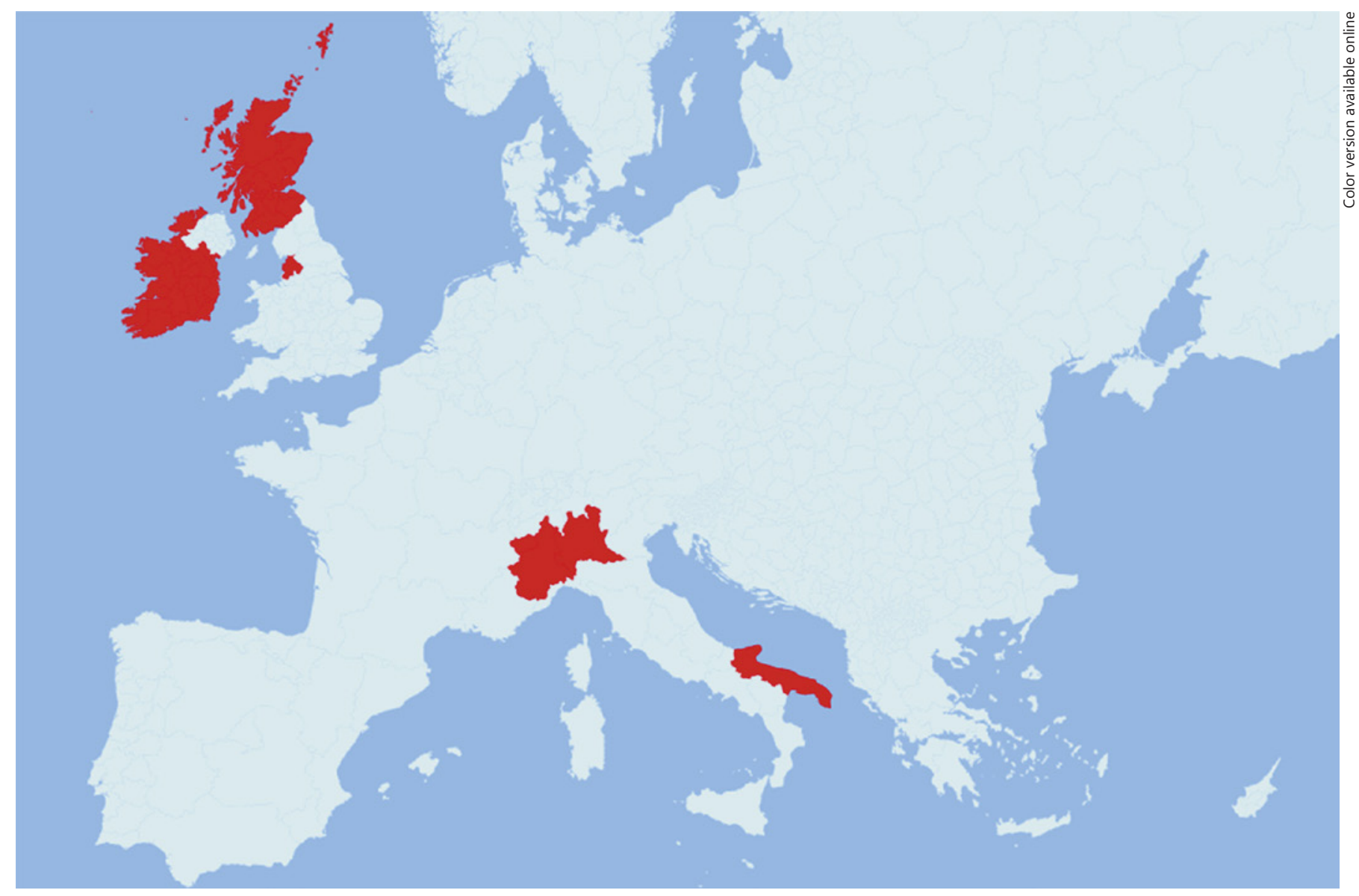

Fig. 1. Geographical areas covered by EURALS consortium registries. Created with mapchart.net.

In each European register, however, only 60-100 cases were collected each year because of the relatively low incidence of the disease and the limited size of the reference population. A larger sample size is required to answer complex questions such as the role of aging and the drop of the incidence curve at age 75 . Similarly, a bigger sample size and diverse population are needed to explore the role of environmental risk factors, genetic variants, and ancestries.

In a meeting in October 2004, a consortium of all European population-based registries was established in Amsterdam; this consortium was named EURALS (Fig. 1). The use of the same diagnostic criteria (EEC), multiple sources, and the prospective inception of incident cases in a defined catchment area were the common characteristics of all European registries in the new consortium. The source population ranged from about $1 \frac{1}{2}$ million in Lancashire to 5 million in Scotland. The characteristics of care were heterogeneous: the density of neurologists was relatively low in Scotland, Lancashire, and Ireland, while it was with a high number of neurological department, neurophysiology centers, and neurologists in Italy. Regions like Lombardia and Puglia count several ALS centers in the same geographic areas making paradoxically more challenging building up an effective network of participating centers to track the cases.

In the year 1998-99, the largest number of ALS incident cases were drawn from a source population comprising almost 24 million people across Europe (ALS cases: 1028) [11]: the estimated incidence was 2.16 per 100,000 py for the general population and 2.7 per 100,000 py for the population over 18 years with a ratio male to female 1.3. In this study, there was a clear confirmation of the drop of incidence after age 75 first for males and afterwards for females compared to information from the oldest studies. Overall, the incidence was relatively similar across some European Ethnicities: Celtic, Anglo- 
Table 1. Incidence rates of ALS in 5 EURALS registries. Incidence rates are standardized on the 45-74 years US 1990 population. Data from Beghi et al. [6], 2007

\begin{tabular}{lllll}
\hline Region & Years & $\begin{array}{l}\text { Incidence males } \\
\text { (per 100,000 py) }\end{array}$ & $\begin{array}{l}\text { Incidence females } \\
\text { (per 100,000 py) }\end{array}$ & $\begin{array}{l}\text { Incidence total } \\
\text { (per 100,000 py) }\end{array}$ \\
\hline Scotland & 1989 & 6.7 & 3.8 & 5.2 \\
Ireland & $1995-1997$ & 6.7 & 5.3 & 6.0 \\
Piemonte & $1995-1996$ & 6.1 & 4.7 & 5.4 \\
Lombardy & $1998-2002$ & 5.1 & 3.5 & 4.2 \\
Puglia & $1998-1999$ & 5.5 & 2.9 & 4.1 \\
\hline
\end{tabular}

Saxon, and diverse populations around the Mediterranean areas (age-standardized incidence rates of EURALS registries are shown in Table 1).

Successive work in new population-based registers has revealed new important features of ALS epidemiology. In the registry of Limousin region in France, the use of capture recapture method has shown that there is the possibility of estimating the number of missing cases and the exhaustiveness of case ascertainment in a registry that surveys a relatively small area. In a first study, Preux and Coll have shown that incidence could be as high as 4.9 per 100,000 py in Limousin using partial information from 3 different independent sources [12]. In a successive study in the same geographic area, the crude incidence has been estimated at 3.2 (2.6 standardized to the European Population) per 100,000 py and the completeness of the register has been estimated at $98.4 \%$ (95\% CI 95.6-99.4) by capture-recapture analysis.

This work shows that the presence of a registry improves case inception over time. The rates, calculated with the support of the capture recapture technique, have clearly indicated the changing age patterns of ALS onset in ageing populations.

Another important issue is that ALS in populationbased studies represents the complete spectrum of ALS phenotypes. Clinical series are more likely to draw subjects that are younger, less likely to present a bulbar onset, with a higher proportion of cases with a positive family history and a more benign course [13]. A series of elements determine the referral pattern to an ALS center in a territory including (1) the organization of ALS care at the national and local level; (2) the availability of local healthcare infrastructure including specific electromyography and MRI; (3) specialized care among local neurologists; (4) knowledge of MND among general practitioner (5) cultural and socioeconomic status of the patients; (6) physical independence and ability to go to ALS referral center; and (7) distance to the center and accessibility.
Some patients will not be referred to the tertiary multidisciplinary center and, therefore, will be probably missed by the registry. In recent estimates, 5 out of 6 patients attend the multicenter clinic on Limousin, while 2 out of 3 visited the clinic in Puglia and Ireland.

The identification of all cases is advantaged by the presence of a multidisciplinary ALS center serving a relatively small geographic area with a limited population, with free access to care in a national health system. With the presence of a registry, the number of patients attending a multidisciplinary clinic is likely to increase over time [13].

An important issue is the difference in the course of disease between cases attending a clinical tertiary center and cases who are part of the real world of populationbased studies. In RCT, subjects who are younger, with a spinal form and with a more benign course are more likely to be enrolled. This systematic difference in prognosis has been clearly shown comparing subjects in the same territory enrolled in RCT and in a populationbased registry [14]. In Piemonte and Val d'Aosta, Italy, subjects in RCT had a survival difference of about 1 year compared to subjects in the population-based registry in the same territory. This enrolment difference is particularly relevant in a disease with short duration like ALS. The lack of power of RCT to show positive results can be at least partly due to the issue of selective participation of patients with better prognosis in clinical trials.

\section{The Geographic Gradient and Ethnic Diversity}

A relevant question to understand causation is if ALS incidence varies depending on the geographical location. Many studies have hypothesized a north-to-south gradient or even an east-to-west gradient. The answer is difficult because these differences are due to underlying risk
Logroscino/Piccininni 
factors or due to the different characteristics of the health system in different regions.

In homogeneous ethnic regions, the oldest studies show lower rates with an incidence even lower than 1 per 100,000 py. In London, the incidence stood at 1.2 per 100,000 py when using the original EEC and it became 1.07 per 100,000 py when using the Revised Arlie House criteria [15].

Some studies suggested that an element playing a key role in the incidence of ALS might be the latitude gradient [16]. In Italy, this was described in an ecologic study highlighting a higher ALS incidence rate in northern areas compared to southern ones adjusting for demographic composition [16]. Moreover, the study did not show a lower ALS incidence in people emigrated from southern regions to the north, but surprisingly, it found the opposite [16]. Likewise, findings of another study conducted in London did not detect a significant incidence rates difference between people with European and African ancestries living in the city [17].

A study of ALS mortality over 30 years (1969-1998) in the United States involving 105,000 deaths with diagnosis based on death certificates, studied incidence difference across 12 geographic regions. This study showed a declining trend from north west to south east in ALS mortality. The differences in ethnic structure of the population with increasing mixed population going from North West to south East may be due to a gradient of ALS genetic risk [18]. More recently a clinical study based on a hospitalbased registry [19] conducted in Sweden showed a gradient with higher risk in the North and lower risk in the South. Accordingly, in Spain, a mortality study with about 9500 ALS deaths showed a decreasing gradient North-South over 15 years [55].

Studies on homogeneous ethnic populations may also give important information. In a study in Ireland based on spatial Bayesian analyses, there was the description of 2 areas of high incidence, one in the regions North Dublin, Louth, Meath, and Cork, relatively economically developed and with higher population density [20] and another one in the Kerry and Donegan, rural areas with an isolated low density population. Interestingly, the authors describe the presence of interaction with age by geographic area. Those aged below 55 have a higher risk in the Kerry and Donegal, while those over age 55 have the highest risk in the Dublin and Cork areas. Therefore, the youngest ALS with a high genetic risk are more likely to be found in the isolated rural areas, while the older cases are more likely to be found in areas characterized by high density. This may be due to a founder effect in these isolated areas and the involvement of different environmental factors in urban areas.

In the United States, a recent study explored ALS heterogeneity in incidence in a relatively small area, New Jersey, in a 3-year period (2009-2011) [21]. In the geographic through spatial Bayesian analyses, the risk of ALS was significantly higher in the highest income quartile than in the lowest (relative risk [RR] 1.4, 95\% CI $1.02-1.82$ ) and lower among blacks (RR 0.57, 95\% CI $0.39-0.83$ ) and Asians (RR 0.63, 95\% CI 0.41-0.97) than among whites. This study that was conducted in a country with large socioeconomic status (SES) diversity, like the United States, showed that ALS risk is linked at the same time to SES and race.

An ALS study was conducted in Cuba. This country is characterized by an extremely heterogeneous ethnic population and a free national health system with a high standard; therefore, here, SES will not determine the referral to the medical system. The ethnic composition based on self-assessment is $65 \%$ mixed, $10 \%$ black, and $25 \%$ white. The mortality due to ALS was identified through death certificates of the National Statistics Mortality system [22] and mortality was considered a surrogate of incidence. ALS mortality was 0.8 per 100,000 py - the lowest in the population of mixed ancestry ( 0.55 per 100,000 py) compared to that of whites (0.93 per 100,000 py) and blacks ( 0.87 per 100,000 py). The mortality rate from ALS in Cuba is similar to that described in Hispanic populations in the United States and is much lower than that in Northern European population. This may be due to a role of ethnicity or ancestry in the ALS etiology.

All these studies indicate that part of the diversity may be determined by ancestries and the underlying genetic variation. At the same time, ethnicities are also probably linked to a different distribution of environmental risk factors.

A recent meta-analysis of ALS incidence rates, adjusted by age and sex, pooled studies from 45 geographic areas [23]. The large majority of the studies were in Europe (about 50\%) and North America (30\%). Some areas had no studies (Sub-Saharian Africa) and many large areas had one or few studies (Latin America, Asia); the incidence in northern Europe standardized on the US 2010 population was 1.89 per 100,000 py, while the standardized incidence in the South of Europe was 1.75. However, in East Asia, the incidence was much lower at 0.89 and in South Asia at 0.79 per 100,000 py. In the Caribbean, the incidence was 1.19 per 100,000 py. In New Zealand, in the southern hemisphere with an Anglosaxon and Celtic population, standardized incidence was particularly high 
(2.29 per 100,000 py). Overall, the pooled ALS standardized incidence for populations of European origin in Europe, North America, and New Zealand showed an extremely homogeneous rate (1.81 per 100,000 py). Conversely, there was a strong heterogeneity between Asia and Europe/ North America for lowest rates in Asian countries. In South America, there were intermediate rates ( 1.59 per 100,000 py). If we consider geographic areas a surrogate, at least partially, of ethnicities, from this extremely complex study, there is a clear indication for ethnic variation. Most of the previous studies from the United States and the United Kingdom indicate a lower risk in non-Whites compared to Caucasians [24, 25]. Lack of referral may determine under ascertainment of minority cases in countries where minorities have a disadvantaged status. The consistency of the findings, with non-caucasian presenting lower incidence, in different countries with different organization of the health system make the referral bias less likely.

Some ALS clinical features are strongly influenced by the geographic area. The survivorship in published studies varied from around 25 months in Northern Europe to around 30 months in Western/Southern Europe. Survivorship was longer in North America [26] and much longer in Asia (particularly in Iran where it was 48 months). The bulbar onset was much more common in Northern Europe (45\%) than in Southern Europe (30\%). In Asia, it was even less common and this difference may explain, at least partially, the difference in survivorship across continents. The proportion of familial cases was on average between 4 and 5\% but higher in Northern and Western Europe compared to the South and this could be related to the variability of the genetic risk in Europe [27]. However, the extreme variability and the disagreement in the field about the definition of familial ALS is something that is worthwhile to mention [28].

Another important element in the direction of studying differences across areas that has been recently and accurately described in a pooled meta-analysis [29] is the age of onset. The variation of ALS rates with age in populations of European origin showed a peak, which was of 7 and 8.2 per 100,000 py at 71.6 and 77.4 years of age, respectively, in Europe and North America.

The peak of ALS incidence in East Asia was estimated to be around 75 years of age, which is in the same age range as that in the population of Caucasian origin but it was at 2.2 per 100,000 py. This difference represents a reduction in risk of more than 3 times in the age range of higher risk going from Caucasian to Chinese populations. It is important to underline, however, that there is peak heterogeneity within areas of North America and Northern Europe compared to homogeneity of peaks in Western and South Europe. The difference in the age peak indicates that the distribution of risk factors linked to geographic areas is uneven across age between Asia and Europe and North America. One of the risk factors with a well-described age penetrance is C9ORF72 [30] and the different prevalence of this gene or other unknown genes may be one of the sources of discrepancy in the height of incidence peak in different geographic areas.

\section{C9orf72 and Geographic Spreading of Genetic Risk}

C9ORF72 is the most common known gene that is associated with ALS, explaining about $40 \%$ of familial cases and $8 \%$ of sporadic [31] in European and North American populations. Similar rates are reported for the association between C9ORF72 and fronto-temporal dementia (FTD), linking to the same gene 2 apparent distinct phenotypes. The prevalence of C9ORF72 in ALS cases is much lower in East (less than 4\% in Japan) [32] and South Asia (5.9\% among familial and $1.6 \%$ among sporadic in Iran) [33]. Behavioral clinical features are more common in ALS and FTD with C9ORF72 mutation. In a large clinical series in the United Kingdom, 38\% of patients with mutation had psychosis and $28 \%$ were with delusional, paranoid thoughts, while only $4 \%$ presented these features among noncarriers.

C9ORF72 is a common gene but with particular high prevalence in Finland [34].

Finland has one of the highest ALS incidences in the world [35]. The mutation happened suddenly in Scandinavia 1,500 years ago and from there it spread. The Viking migration is the main source of the spreading of C9ORF72 in Europe and North America. The belligerent attitude and lack of empathy were drivers of Viking conquests and were probably partly caused by the presence of C9ORF72 mutations.

Pliner et al. [31] speculate that similar features were determined in other populations like in the United Kingdom by MAPT mutations then found in British colonies like Australia, British Columbia Virginia: this mutation probably raised 500 years ago in Wales. Similarly, a different distribution of the C9ORF72 mutation was well described in the United States with a highest prevalence in Midwest where there is presence of numerous individuals of Scandinavian descent [36]. C9ORF72 is the strongest hint that part of the geographic distribution across geographic areas may be of genetic origin.
Logroscino/Piccininni 


\section{ALS Foci in the World}

On the island of Guam, in the early fifties of the last century, that is, in the 1950s, the ALS incidence was close to 100 per 100,000 py and was the highest in the world [37]. Starting in the 1960s, the incidence of ALS dropped dramatically to incidence ( 3 per 100,000 py) similar to that of Europe and North America.

A second phenotype, Parkinsonism-dementia complex (PDC) of Guam cluster peaked to 60 per 100,000 py in the early sixties and declined afterwards reaching 10 per 100,000 py in the eighties. The other foci were in the Kiji peninsula in Japan where, as in Guam [38], both phenotypes were present. The incidence has decreased substantially in Kii in the 1980s and 1990s with PDC becoming more prevalent.

The incidence and prevalence of both ALS and PDC have decreased but is still high in New Guinea, the third foci [39], probably a prevalence of at least around 73 per 100,000 for pure ALS and 53 for PDC [40]. It is worthwhile to mention that at the time of the peak of incidence, the estimated incidence in Papua, New Guinea was 30 times that in Guam and Kii and 100 times that in the rest of the world [41].

Thus, ALS/PDC both in Guam and in the Kii Peninsula is probably a single disease characterized neuropathologically by a multiple proteinopathy due to TDP43, synuclein, and tau deposition. The clinical features are linked to the predominant protein: TDP43 with motor neuron, tau, and alphasynuclein with PDC. The genes involved in ALS and PDC in Guam are at least partially the same as in Western countries [42] but neither C9ORF72 nor LRKK2 are involved in ALS and PDC among Chamorros [43].

There were several isolated ethnicities involved in these foci: Chamorros of Guam, Rota, Japanese residents of Kii Peninsula, and Honshu, Auyu and Jaqai linguistic groups in West Papua, Indonesia [44]. The involvement of selected ethnicities may indicate that a common genetic predisposition is present and that it is a driving part of the risk.

The fast and constant decrease in ALS incidence, and partially PDC incidence, over 60 years is not due to the genetic factors that need many generations to manifest. Instead, environmental, life style linked to the rapid westernization of Guam and of the other territories is likely to be the basis of the change. Incidence fall is perhaps related to the removal of an unknown exposure. One of the most debated hypotheses has been the dietary intake of a cyanobacterial toxin present in the traditional Chamorro

ALS Descriptive Epidemiology: The

Origin of Geographic Difference diet, $\beta$-N-methylamino-l-alanine. There are basic laboratory and animal evidences that this compound promotes both NFT and $\beta$-amyloid deposits $[45,46]$, similar to the deposit found in the brain of Chamorros affected individuals.

Recently a case of a 76-year old Japanese man migrating from Kii when he was 3 years old and manifesting PDC 70 years later was reported [47]. This case underlines the importance of both genetics and early life environmental factors. In this case, the possible exposure to an environmental factor was extremely short.

\section{The Global Burden of Disease: ALS in the World in the Future Decades}

The Global Burden of Disease (GBD) is a project aiming at describing the burden of all diseases and injuries across all the countries of the world, with a standardized protocol and same instruments of measurements. Information on epidemiology, social effects, and risk factors distribution is essential to plan health interventions and support health decision processes at the global and national level.

GBD also introduced a new measure aiming at summarizing the overall burden of a disease: the Disability Adjusted Life Year (DALY). This measure is the sum of the number of years lived with disability and the number of years lost due to death compared to life expectation.

In order to summarize valid information, the GBD takes into account all available data on specific diseases, from national mortality registries to published epidemiological studies. Advanced statistical techniques are used to account for inconsistencies and lack of data.

In GBD, ALS is included in the MND category with other very rare motor neuron pathologies.

According to new GBD data, in 2016, there were around $331(300-367)$ thousand prevalent cases and 58 (52-63) thousand incident cases of MND across the world [48]. In 2015 , this neurodegenerative disease caused about 910 (872-959) thousands of DALYs around the world [49]. This high burden of MND is the result of a sharp increase in prevalent cases over the last years. Globally, the number of MND prevalent cases increased by $72.4 \%$ (69.2-75.2) from 1990 to 2015, while the number of deaths due to MND increased by $97.3 \%$ (73.9-103.6) in the same period [49]. In absolute terms, this increase appears to be massive if we consider that from 1990 to 2015, the world population "only" increased by around $40 \%$.

Neuroepidemiology 2019;52:93-103 DOI: $10.1159 / 000493386$ 


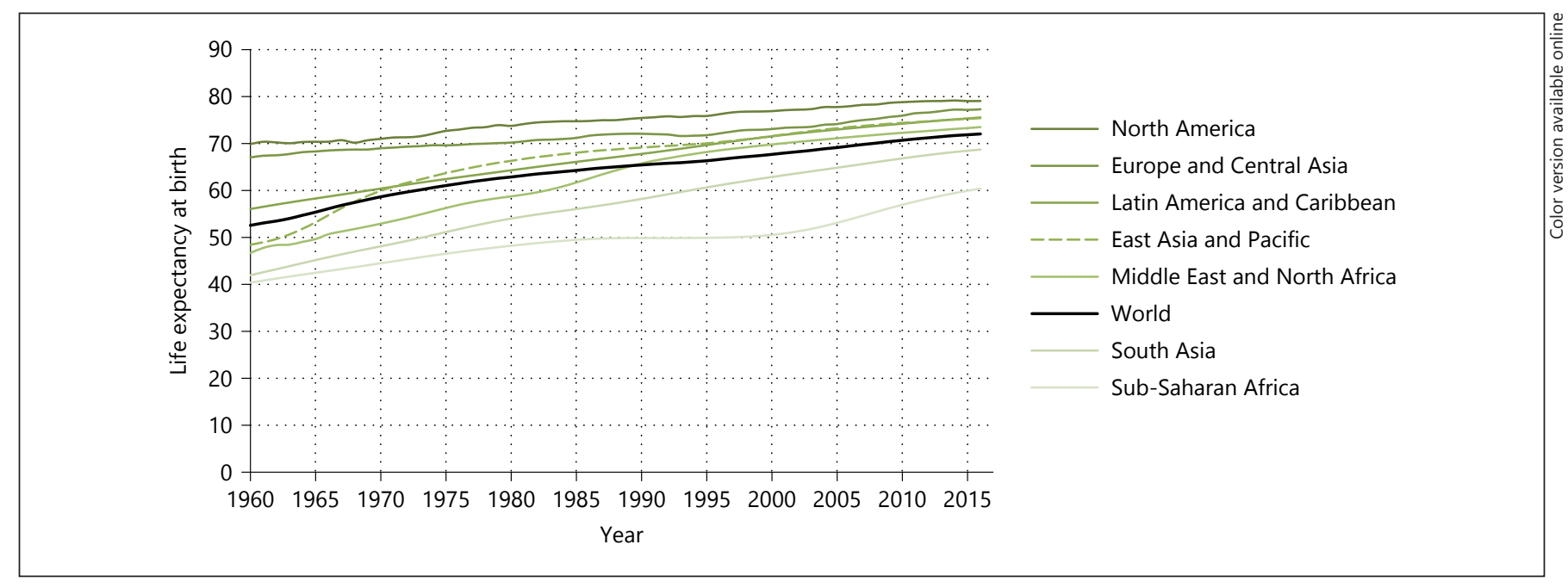

Fig. 2. Life expectancy at birth from 1960 to 2016 in the World and 7 geographical regions. Data from World Bank Open Data (https://data.worldbank.org/).

Table 2. Number of estimated prevalent cases in 2015 and 2040 (expected) in ten geographical regions. Data from Arthur et al. [50], 2016

\begin{tabular}{lrrl}
\hline Country & 2015 & 2040 & $\begin{array}{l}\text { Change in prevalent } \\
\text { cases number, \% }\end{array}$ \\
\hline Libya & 293 & 635 & 116.7 \\
United States & 21,835 & 29,306 & 34.2 \\
Uruguay & 207 & 269 & 30.0 \\
China & 20,329 & 29,734 & 46.3 \\
Iran & 1,409 & 2,992 & 112.3 \\
Japan & 5,866 & 6,431 & 9.6 \\
Taiwan & 622 & 796 & 28.0 \\
EU 28 & 29,208 & 35,024 & 19.9 \\
Serbia & 126 & 117 & -7.1 \\
New Zealand & 265 & 391 & 47.5 \\
\hline
\end{tabular}

As for the cause of this MND prevalence increase, another important GBD result needs to be mentioned: the age-standardized prevalence of MND increased only by $3.1 \%$ from 1990 to 2015 [49]. This change explains a small part of the observed prevalence increase.

It is well known that ALS has been recording an increasing incidence over the years, with a peak around the age of 75 [23]. In the next future, ageing of the world population will drive the ALS burden. A recent study tried to estimate future changes using data from 10 geographical regions covering $34 \%$ of the world population (China, Europe, Iran, Japan, Libya, New Zealand, Serbia, Taiwan, US and Uruguay). First, expected prevalent cases in the 10 selected regions were estimated (Table 2). Then, by applying incidence data from these countries to their respective continents, 222,801 cases of ALS were estimated in 2015. The projections for the future indicate an estimated number of 376,674 ALS prevalent cases in 2040, with an increase of $69 \%$ in only 25 years [50]. This increase will be mainly due to worldwide population ageing and growth that occurs not homogeneously. It has been estimated that the $80 \%$ of the elderly population worldwide will reside in developing countries by 2050 [51]. Indeed, the proportion of older people in developing countries will increase from 9 to $16 \%$ in the period from 2015 to 2040 [51]. China, India, Brazil, Indonesia, Pakistan, Nigeria, Bangladesh, and Ethiopia are countries with high demographic impact and rapidly increasing expectation of life. For this reason, the increase in ALS prevalent cases is estimated to be higher in developing countries than in developed countries, considering the fact that life expectancy at birth in developing countries is quickly reaching the values characterizing high-income countries (Fig. 2).

Over the next 25 years, the highest change in ALS cases will be in Africa, with an increase of $116 \%$, followed by Asia and South America with an increase of 81 and $73 \%$ [50]. The natural consequence of differential ageing and differential increase in the population size is the gradual shift of the ALS burden from developed to developing countries in the next few decades. This scenario requires the implementation of health interventions and a new resources allocation at the global level. 


\section{Conclusions}

The analyses of geographic variations in the prevalence and incidence of several chronic conditions, such as hypertension, diabetes, obesity, cerebrovascular and cardiovascular diseases are a critical tool to identify area of unusual frequency. This has been done in the past both to promote public health intervention and to better understand the causes of disease. An example of this has been the health program in Karelia, Finland, after the discovery of a high rate of cardiovascular disease [52, 53].

The targeted health promotion campaigns, yet still rarely performed, are an experimented approach in common chronic diseases. This is a possible approach already done in common chronic neurodegenerative diseases as dementia, at least in research.

This type of geographic approach could be useful also in rare neurodegenerative diseases as ALS. The comparison of differences may help to discover better understanding of causes of these diseases. In this scenario, the approach of GBD and registries are different and at the same time complementary for better analytic epidemiology and to allocate resources for these diseases. The most difficult challenge of epidemiological research is that is not possible in general to separate the role of ancestry/ ethnicity origin from risk factors depending on lifestyle or environment because they are closely associated. In the future, the most useful studies will be in mixed populations, but they are very difficult to design because of the possible role of socio-economic status that needs to be taken into consideration. In this perspective, LAENALS, the new project to study ALS epidemiology in South America, studying diverse ethnicities in the same territory could be a further step. In contrast, the analyses of highly homogeneous communities as Albanians in the NDAL project in Albania and Kosovo, with the same methodology could complete the diversity of information, using the same registry methodology [54]. All these new initiatives from neglected areas may improve the quality of estimation of descriptive measures (incidence and prevalence) and consequence of disease (DALYs) in more general initiatives like the GBD project. The projections indicate that the future burden of ALS cases will shift towards Asia and Africa because of the demographic trend. Public health consequences and the need for a different allocation of resources are evident.

\section{Acknowledgments and Funding Source}

We thank Dr. Marco Musio for the technical assistance in the preparation of the paper. G.L. and M.P. are supported in their work on ALS and rare neurological diseases by a special grant from Regione Puglia (DGR n. $1284-27.05 .2015)$ for the project "Registro Regionale per la SLA, la FTD-P e le patologie affini in Regione Puglia" (SLAPDem register- www.slapdem.it).

\section{Disclosure Statement}

The authors declare no conflicts of interest to disclose.

\section{References}

1 Al-Chalabi A, Hardiman O, Kiernan MC, Chio A, Rix-Brooks B, van den Berg LH: Amyotrophic lateral sclerosis: moving towards a new classification system. Lancet Neurol 2016;15:1182-1194.

2 The Scottish Motor Neuron Disease Register: a prospective study of adult onset motor neuron disease in Scotland. Methodology, demography and clinical features of incident cases in 1989. J Neurol Neurosurg Psychiatry 1992;55:536-541.

3 Mitchell JD, Gibson HN, Gatrell A: Amyotrophic lateral sclerosis in Lancashire and South Cumbria, England, 1976-1986. A geographical study. Arch Neurol 1990;47:875880.

4 Traynor BJ, Codd MB, Corr B, Forde C, Frost E, Hardiman O: Incidence and prevalence of ALS in Ireland, 1995-1997: a population-based study. Neurology 1999;52:504509.
5 Incidence of ALS in Italy: evidence for a uniform frequency in Western countries. Neurology 2001;56:239-244.

6 Beghi E, Millul A, Micheli A, Vitelli E, Logroscino G: Incidence of ALS in Lombardy, Italy. Neurology 2007;68:141-145.

7 Logroscino G, Beghi E, Zoccolella S, Palagano R, Fraddosio A, Simone IL, Lamberti $\mathrm{P}$, Lepore V, Serlenga L: Incidence of amyotrophic lateral sclerosis in southern Italy: a population based study. J Neurol Neurosurg Psychiatry 2005;76:10941098.

8 https://www.patientslikeme.com/(accessed August 9, 2018).

9 Traynor BJ, Codd MB, Corr B, Forde C, Frost E, Hardiman O: Amyotrophic lateral sclerosis mimic syndromes: a population-based study. Arch Neurol 2000;57:109-113.

10 Logroscino G, Traynor BJ, Hardiman O, Chio A, Couratier P, Mitchell JD, Swingler RJ, Be- ghi E: Descriptive epidemiology of amyotrophic lateral sclerosis: new evidence and unsolved issues. J Neurol Neurosurg Psychiatry 2008;79:6-11.

11 Logroscino G, Traynor BJ, Hardiman O, Chio A, Mitchell D, Swingler RJ, Millul A, Benn E, Beghi E: Incidence of amyotrophic lateral sclerosis in Europe. J Neurol Neurosurg Psychiatry 2010;81:385-390.

12 Preux PM, Druet-Cabanac M, Couratier P, Debrock C, Truong T, Marcharia W, Vallat JM, Dumas M, Boutros-Toni F: Estimation of the amyotrophic lateral sclerosis incidence by capture-recapture method in the Limousin region of France. J Clin Epidemiol 2000;53: 1025-1029.

13 Logroscino G, Marin B, Piccininni M, Arcuti S, Chio A, Hardiman O, Rooney J, Zoccolella S, Couratier P, Preux PM, Beghi E: Referral bias in ALS epidemiological studies. PLoS One 2018;13:e0195821.
ALS Descriptive Epidemiology: The

Origin of Geographic Difference
Neuroepidemiology 2019;52:93-103 DOI: $10.1159 / 000493386$ 
14 Chio A, Canosa A, Gallo S, Cammarosano S, Moglia C, Fuda G, Calvo A, Mora G: ALS clinical trials: do enrolled patients accurately represent the ALS population? Neurology 2011; 77:1432-1437.

15 Johnston CA, Stanton BR, Turner MR, Gray $\mathrm{R}$, Blunt AH, Butt D, Ampong MA, Shaw CE, Leigh PN, Al-Chalabi A: Amyotrophic lateral sclerosis in an urban setting: a population based study of inner city London. J Neurol 2006;253:1642-1643.

16 Chio A, Cucatto A, Calvo A, Terreni AA, Magnani C, Schiffer D: Amyotrophic lateral sclerosis among the migrant population to Piemonte, northwestern Italy. J Neurol 1999; 246:175-180.

17 Rojas-Garcia R, Scott KM, Roche JC, Scotton W, Martin N, Janssen A, Goldstein LH, Leigh PN, Ellis CM, Shaw CE, Al-Chalabi A: No evidence for a large difference in ALS frequency in populations of African and European origin: a population based study in inner city London. Amyotroph Lateral Scler 2012;13: 66-68.

18 Noonan CW, White MC, Thurman D, Wong LY: Temporal and geographic variation in United States motor neuron disease mortality, 1969-1998. Neurology 2005;64:12151221.

19 Fang F, Valdimarsdottir U, Bellocco R, Ronnevi LO, Sparen P, Fall K, Ye W: Amyotrophic lateral sclerosis in Sweden, 1991-2005. Arch Neurol 2009;66:515-519.

20 Rooney J, Byrne S, Heverin M, Corr B, Elamin M, Staines A, Goldacre B, Hardiman O: Survival analysis of irish amyotrophic lateral sclerosis patients diagnosed from 1995-2010. PLoS One 2013;8:e74733.

21 Henry KA, Fagliano J, Jordan HM, Rechtman L, Kaye WE: Geographic variation of amyotrophic lateral sclerosis incidence in New Jersey, 2009-2011. Am J Epidemiol 2015;182: 512-519.

22 Zaldivar T, Gutierrez J, Lara G, Carbonara M, Logroscino G, Hardiman O: Reduced frequency of ALS in an ethnically mixed population: a population-based mortality study. Neurology 2009;72:1640-1645.

23 Marin B, Boumediene F, Logroscino G, Couratier $\mathrm{P}$, Babron MC, Leutenegger AL, Copetti M, Preux PM, Beghi E: Variation in worldwide incidence of amyotrophic lateral sclerosis: a meta-analysis. Int J Epidemiol 2017;46: 57-74.

24 Annegers JF, Appel S, Lee JR, Perkins P: Incidence and prevalence of amyotrophic lateral sclerosis in Harris County, Texas, 1985-1988. Arch Neurol 1991;48:589-593.

25 McGuire V, Longstreth WT, Jr., Koepsell $\mathrm{TD}$, van Belle G: Incidence of amyotrophic lateral sclerosis in three counties in western Washington state. Neurology 1996;47:571573.

26 Marin B, Logroscino G, Boumediene F, Labrunie A, Couratier P, Babron MC, Leutenegger AL, Preux PM, Beghi E: Clinical and demographic factors and outcome of amyo- trophic lateral sclerosis in relation to population ancestral origin. Eur J Epidemiol 2016;31:229-245.

27 Byrne S, Bede P, Elamin M, Kenna K, Lynch C, McLaughlin R, Hardiman O: Proposed criteria for familial amyotrophic lateral sclerosis. Amyotroph Lateral Scler 2011;12:157159.

28 Byrne S, Elamin M, Bede P, Hardiman O: Absence of consensus in diagnostic criteria for familial neurodegenerative diseases. J Neurol Neurosurg Psychiatry 2012;83:365-367.

29 Marin B, Fontana A, Arcuti S, Copetti M, Boumediene F, Couratier P, Beghi E, Preux PM, Logroscino G: Age-specific ALS incidence: a dose-response meta-analysis. Eur J Epidemiol 2018;33:621-634.

30 Murphy NA, Arthur KC, Tienari PJ, Houlden $\mathrm{H}$, Chio A, Traynor BJ: Age-related penetrance of the C9orf72 repeat expansion. Sci Rep 2017;7:2116.

31 Pliner HA, Mann DM, Traynor BJ: Searching for Grendel: origin and global spread of the C9ORF72 repeat expansion. Acta neuropathol 2014;127:391-396.

32 Konno T, Shiga A, Tsujino A, Sugai A, Kato T, Kanai K, Yokoseki A, Eguchi H, Kuwabara S, Nishizawa M, Takahashi H, Onodera O: Japanese amyotrophic lateral sclerosis patients with GGGGCC hexanucleotide repeat expansion in C9ORF72. J Neurol Neurosurg Psychiatry 2013;84:398-401.

33 Alavi A, Nafissi S, Rohani M, Shahidi G, Zamani B, Shamshiri H, Safari I, Elahi E: Repeat expansion in C9ORF72 is not a major cause of amyotrophic lateral sclerosis among Iranian patients. Neurobiol Aging 2014;35:267.e261e267.

34 Chio A, Restagno G, Brunetti M, Ossola I, Calvo A, Canosa A, Moglia C, Floris G, Tacconi P, Marrosu F, Marrosu MG, Murru MR, Majounie E, Renton AE, Abramzon Y, Pugliatti M, Sotgiu MA, Traynor BJ, Borghero G: ALS/FTD phenotype in two Sardinian families carrying both C9ORF72 and TARDBP mutations. J Neurol Neurosurg Psychiatry 2012;83:730-733.

35 Murros K, Fogelholm R: Amyotrophic lateral sclerosis in Middle-Finland: an epidemiological study. Acta Neurol Scand 1983; 67:41-47.

36 Harms MB, Cady J, Zaidman C, Cooper P, Bali T, Allred P, Cruchaga C, Baughn M, Libby RT, Pestronk A, Goate A, Ravits J, Baloh RH: Lack of C9ORF72 coding mutations supports a gain of function for repeat expansions in amyotrophic lateral sclerosis. Neurobiol Aging 2013;34:2234.e2213e2239.

37 Plato CC, Garruto RM, Galasko D, Craig UK, Plato M, Gamst A, Torres JM, Wiederholt W: Amyotrophic lateral sclerosis and parkinsonism-dementia complex of Guam: changing incidence rates during the past 60 years. Am J Epidemiol 2003;157:149-157.

38 Mimuro M, Yoshida M, Kuzuhara S, Kokubo $\mathrm{Y}$ : Amyotrophic lateral sclerosis and parkin- sonism-dementia complex of the Hohara focus of the Kii Peninsula: a multiple proteinopathy? Neuropathology 2018;38:98107.

39 Spencer PS, Palmer VS, Ludolph AC: On the decline and etiology of high-incidence motor system disease in West Papua (southwest New Guinea). Mov Disord 2005;20 (suppl 12): S119-S126.

40 Okumiya K, Wada T, Fujisawa M, Ishine M, Garcia Del Saz E, Hirata Y, Kuzuhara S, Kokubo Y, Seguchi H, Sakamoto R, Manuaba I, Watofa P, Rantetampang AL, Matsubayashi $\mathrm{K}$ : Amyotrophic lateral sclerosis and parkinsonism in Papua, Indonesia: 2001-2012 survey results. BMJ Open 2014;4:e004353.

41 Gajdusek DC, Salazar AM: Amyotrophic lateral sclerosis and parkinsonian syndromes in high incidence among the Auyu and Jakai people of West New Guinea. Neurology 1982; 32:107-126.

42 Steele JC, Guella I, Szu-Tu C, Lin MK, Thompson C, Evans DM, Sherman HE, Vilarino-Guell C, Gwinn K, Morris H, Dickson DW, Farrer MJ: Defining neurodegeneration on Guam by targeted genomic sequencing. Ann Neurol 2015;77:458-468.

43 Dombroski BA, Galasko DR, Mata IF, Zabetian CP, Craig UK, Garruto RM, Oyanagi K, Schellenberg GD: C9orf72 hexanucleotide repeat expansion and Guam amyotrophic lateral sclerosis-Parkinsonism-dementia complex. JAMA Neurol 2013;70: $742-745$.

44 Spencer PS, Palmer VS, Kisby GE: Seeking environmental causes of neurodegenerative disease and envisioning primary prevention. Neurotoxicology 2016;56:269-283.

45 Cox PA, Davis DA, Mash DC, Metcalf JS, Banack SA: Dietary exposure to an environmental toxin triggers neurofibrillary tangles and amyloid deposits in the brain. Proceed Biol Sci 2016;283.

46 Cox PA, Sacks OW: Cycad neurotoxins, consumption of flying foxes, and ALS-PDC disease in Guam. Neurology 2002;58:956959

47 Tsunoda K, Yamashita T, Shimada H, Nomura E, Takahashi Y, Shang J, Sato K, Takemoto M, Hishikawa N, Ohta Y, Higuchi M, Suhara T, Kokubo Y, Kuzuhara S, Abe K: A migration case of Kii amyotrophic lateral sclerosis/parkinsonism dementia complex with the shortest stay in the endemic area and the longest incubation to develop the disease. J Clin Neurosci 2017;46:64-67.

48 Global, regional, and national incidence, prevalence, and years lived with disability for 328 diseases and injuries for 195 countries, 1990-2016: a systematic analysis for the Global Burden of Disease Study 2016. Lancet 2017; 390:1211-1259.

49 Global, regional, and national burden of neurological disorders during 1990-2015: a systematic analysis for the Global Burden of Disease Study 2015. Lancet Neurol 2017;16:877897. 
50 Arthur KC, Calvo A, Price TR, Geiger JT, Chio A, Traynor BJ: Projected increase in amyotrophic lateral sclerosis from 2015 to 2040. Nat Commun 2016;7:12408.

51 United Nations DoEaSA, Population Division World Population Ageing 2013 - ST/ ESA/SER.A/348. New York, 2013.

52 Puska P: From Framingham to North Karelia: from descriptive epidemiology to public health action. Prog Cardiovasc Dis 2010;53: $15-20$.

53 Logroscino G, Tortelli R: The role of prevention in common neurological disorders; $\mathrm{Ox}$ ford Textbook of Neurologic and Neuropsychiatric Epidemiology, Oxford University Press, in press.

54 Brayne C, Tobin K, Logroscino G, Glymour MM, Hardiman O: Benefits, pitfalls, and fu- ture design of population-based registers in neurodegenerative diseases. Neurology 2017; 88:2321-2329.

55 Alonso V, Villaverde-Hueso A, Hens MJ, Morales-Piga A, Abaitua I, de la Paz MP: Increase in motor neuron disease mortality in Spain: temporal and geographical analysis (1990-2005). Amyotroph Lateral Scler 2011; 12:192-198. 